\title{
Efficacy of adalimumab in young children with juvenile idiopathic arthritis and chronic uveitis: a case series
}

\author{
Francesco La Torre ${ }^{1 *}$, Marco Cattalini ${ }^{2}$, Barbara Teruzzi ${ }^{3}$, Antonella Meini ${ }^{2}$, Fulvio Moramarco ${ }^{1}$ \\ and Florenzo lannone ${ }^{4}$
}

\begin{abstract}
Background: Juvenile idiopathic arthritis is a relatively common chronic disease of childhood, and is associated with persistent morbidity and extra-articular complications, one of the most common being uveitis. The introduction of biologic therapies, particularly those blocking the inflammatory mediator tumor necrosis factor-a, provided a new treatment option for juvenile idiopathic arthritis patients who were refractory to standard therapy such as non-steroidal anti-inflammatory drugs, corticosteroids and/or methotrexate.

Case presentations: The first case was a 2-year-old girl with juvenile idiopathic arthritis and uveitis who failed to respond to treatment with anti-inflammatories, low-dose corticosteroids and methotrexate, and had growth retardation. Adalimumab $24 \mathrm{mg} / \mathrm{m}^{2}$ every 2 weeks and prednisone $0.5 \mathrm{mg} / \mathrm{kg} /$ day were added to methotrexate therapy; steroid tapering and withdrawal started after 1 month. After 2 months the patient showed good control of articular and ocular manifestations, and she remained in remission for 1 year, receiving adalimumab and methotrexate with no side effects, and showing significant improvement in growth. Case 2 was a 9-year-old boy with an 8-year history of juvenile idiopathic arthritis and uveitis that initially responded to infliximab, but relapse occurred after 2 years off therapy. After switching to adalimumab, and adjusting doses of both adalimumab and methotrexate based on body surface area, the patient showed good response and corticosteroids were tapered and withdrawn after 6 months; the patient remained in remission taking adalimumab and methotrexate. The final case was a 5-year-old girl with juvenile idiopathic arthritis for whom adalimumab was added to methotrexate therapy after three flares of uveitis. The patient had two subsequent episodes of uveitis that responded well to local therapy, but was then free of both juvenile idiopathic arthritis and uveitis symptoms, allowing methotrexate and then adalimumab to be stopped; the patient remained in drug-free remission.
\end{abstract}

Conclusion: This report includes the first published case of the use of adalimumab in a child aged $<3$ years. Our clinical experience further supports the use of biologic therapy for the management of juvenile idiopathic arthritis and uveitis in children as young as two years of age.

Keywords: Adalimumab, Juvenile idiopathic arthritis, Children, Uveitis

\section{Background}

Juvenile idiopathic arthritis (JIA) is defined as arthritis of unknown etiology with onset prior to 16 years of age that persists for 6 weeks or longer and is not secondary to any other conditions [1]. Classification of JIA is based on the criteria developed by the International League of Associations for Rheumatology (ILAR) [1,2]. JIA is one of the

\footnotetext{
* Correspondence: latorre_francesco@virgilio.it

'Department of Paediatrics, Antonio Perrino Hospital, Brindisi, Italy

Full list of author information is available at the end of the article
}

more common chronic diseases of childhood [3], and its prevalence in the United States (US) and Northern Europe is estimated to be $7-21$ cases per 100,000 of population [4]. JIA can have an adverse effect on the growth and development of joints and bones, often persists into adulthood and can result in significant long-term morbidity, including physical disability $[3,5,6]$. Factors contributing to growth suppression in JIA include the degree, extent and duration of disease activity, age at onset, immobility, suboptimal nutrition and systemic corticosteroid therapy [5]. 
Standard medical treatment for JIA consists of nonsteroidal anti-inflammatory drugs (NSAIDs), systemic glucocorticoids and/or disease-modifying anti-rheumatic drugs (DMARDs) such as methotrexate. However, up to $30 \%$ of patients do not respond to treatment [7]. A new era in the treatment of JIA arrived with the introduction of biologic therapies, particularly those blocking the inflammatory mediator tumor necrosis factor- $\alpha$ (TNF- $\alpha)$ [8]. Approximately $80 \%$ of patients with active polyarticular disease, despite previous use of non-biologic DMARDs, have been shown to respond to biological drugs, and children treated with biologic therapy feel better and have less pain $[9,10]$. Treatment guidelines in the US now recommend switching to biologic therapy in JIA patients with persistent moderateto-severe disease activity, or drug intolerance, after four months of treatment with standard medical therapy [11]. TNF- $\alpha$ has also been reported to play a role in the pathogenesis of ocular inflammation, with high levels detected in the serum and aqueous humor of patients with uveitis [12-14]. Chronic anterior uveitis is insidious, highly refractory, bilateral in $80 \%$ of patients, often corticosteroiddependent, and associated with high rates of medium- and long-term complications such as posterior synechiae, band keratopathy, cataract and glaucoma $[15,16]$. Overall, 20\% to $25 \%$ of all pediatric uveitis is associated with JIA [17]. Anterior uveitis is the most frequent extra-articular disease associated with JIA $[15,18,19]$. The major risk factors for the development of uveitis in JIA patients are oligoarticular pattern of arthritis, onset of arthritis before 7 years of age and antinuclear antibody positivity [18]. In the initial stages of mild to moderate inflammation, uveitis is entirely asymptomatic. This has led to the current practice of screening all children with JIA regularly for uveitis. Approximately $12 \%$ to $38 \%$ of patients with JIA will develop uveitis in the 7 years following the onset of arthritis [19]. In 30\% to 50\% of children with JIA-associated uveitis, structural complications are present at the time of diagnosis [20]. Furthermore, about $50 \%$ to $75 \%$ of those with severe uveitis will eventually develop visual impairment secondary to ocular complications such as cataract, glaucoma, band keratopathy and macular pathology [21-23]. Early and aggressive intervention is appropriate to prevent irreversible complications and preserve visual acuity.

Significant prognosticators of poor visual acuity include structural changes at presentation, the need for intraocular surgery, posterior segment inflammation, abnormal intraocular pressure and failure to maintain long-term disease control as marked by persistent anterior chamber (AC) cell scores of 1 or higher [20-22,24].

While anti-TNF agents have a significant impact on the management of JIA, experience on their effects on uveitis remains limited, particularly in younger patients. The three cases presented here document the safety and effectiveness of adalimumab in children with JIA and co-morbid uveitis, one of them being, to our knowledge, the first published case report of the use of this biological drug in a child aged $<3$ years.

\section{Case Presentations \\ Case 1}

A 2-year-old girl presented at hospital with JIA and bilateral chronic uveitis. The onset of articular disease was at 8 months of age and the diagnosis of JIA was made at age 14 months. She had previously been treated with injections of triamcinolone hexacetonide into her left knee and left ankle joints, which resulted in temporary disease control, but arthritis relapsed in the same joints after 3 months (Figures 1 and 2). The patient had difficulties in walking and climbing stairs. Anti-inflammatory drugs and low-dose corticosteroids were initiated without benefit. Two months later, at age 19 months, subcutaneous methotrexate $15 \mathrm{mg} /$ $\mathrm{m}^{2} /$ week was added. Arthritis improved, but bilateral chronic anterior uveitis developed after 3 months, despite ongoing methotrexate treatment. The diagnosis was made at the regular ocular screening follow-up, because she didn't show any ocular symptoms, but at slit-lamp examination cells in the anterior chamber were present. Uveitis was initially managed with standard eye care, but several relapses occurred resulting in the formation of bilateral papilledema. Brain magnetic resonance imaging was normal. She had growth retardation (weight $9.8 \mathrm{~kg}\left[<3^{\text {rd }}\right.$ percentile], height $76 \mathrm{~cm}[-3$ standard deviations from normal]) (Figure 3).

The patient was started on treatment with adalimumab $24 \mathrm{mg} / \mathrm{m}^{2}$ every 2 weeks in combination with prednisone

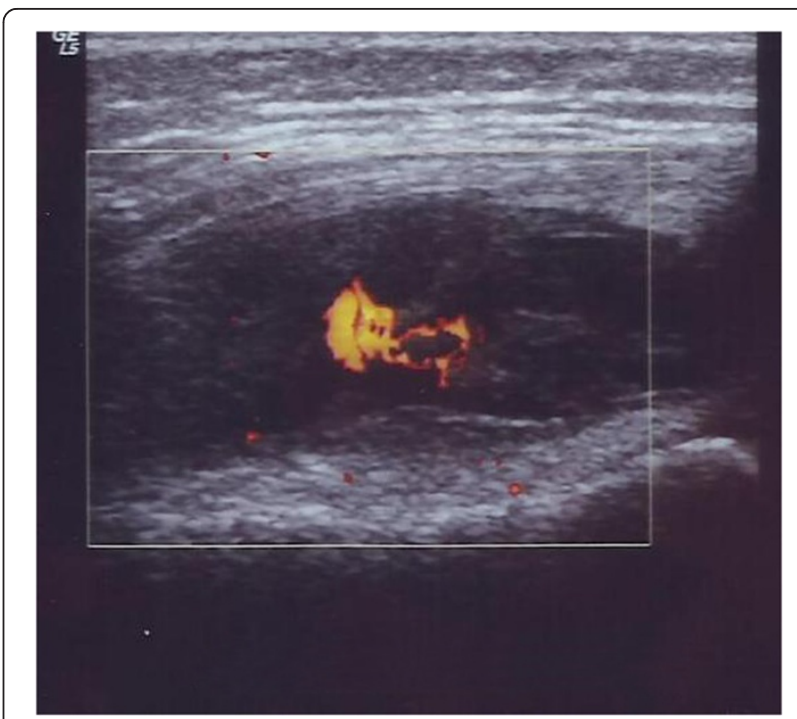

Figure 1 Case 1 left knee ultrasound. Transverse gray-scale and color Doppler 12-5 MHz ultrasound image obtained over the medial aspect of the knee showing abundant synovial pannus filling the subquadriceps recess as a band of hypoechoic tissue intermingled with fluid. Marked synovial hyperemia is observed at color Doppler examination indicating active pannus. 


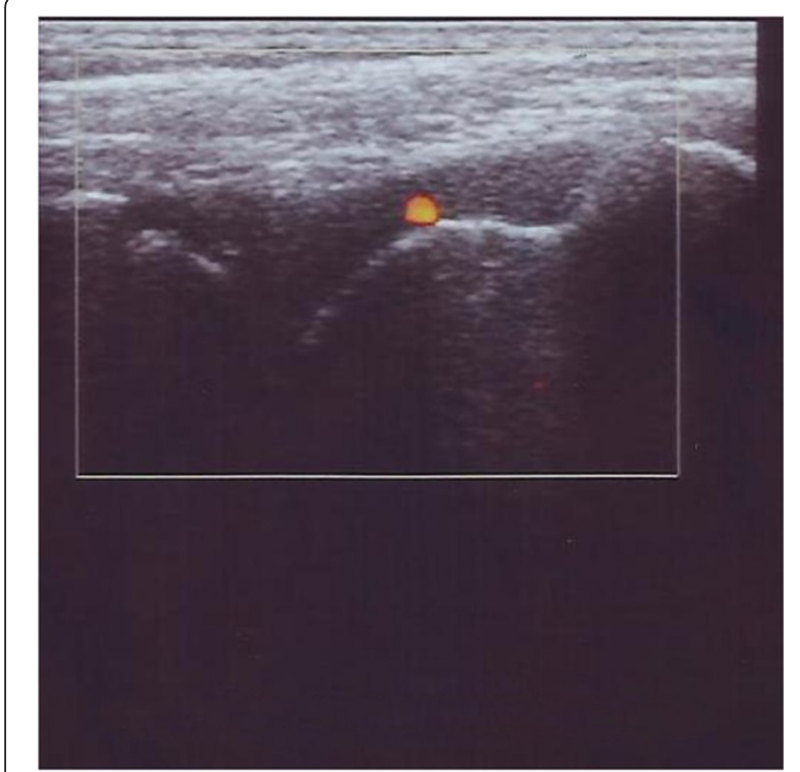

Figure 2 Case 1 left ankle ultrasound. Midsagittal $12-5 \mathrm{MHz}$ ultrasound image over the dorsal ankle shows a distended anterior joint recess, filled with hypoechoic fluid with active synovial pannus as marked by color Doppler examination.

$0.5 \mathrm{mg} / \mathrm{kg} /$ day for one month with subsequent steroid tapering; methotrexate was continued at the same dose. Two months later, both articular and ocular manifestations were well controlled, papilledema had resolved and corticosteroid treatment was stopped (Figures 4 and 5). One year later the patient was still in remission receiving adalimumab and methotrexate, without any side effects. Her growth rate significantly improved in the absence of corticosteroid treatment and with no disease relapses (weight $15 \mathrm{~kg}\left[10^{\text {th }}\right.$ percentile], height $100 \mathrm{~cm}[-1$ standard deviation from normal]) (Figure 6). After two years, methotrexate dose reduction was undertaken.

\section{Case 2}

A boy aged 9 years and 4 months was admitted to hospital in June 2012 with oligo-articular extended-onset JIA and associated chronic bilateral uveitis with posterior synechiae. Immune serology was positive for antinuclear antibodies (ANA) and human lymphocyte antigen (HLA) B27, while rheumatoid factor (RF) was negative. Age at disease onset was 1 year 9 months, when the patient presented with bilateral anterior uveitis with eyes redness and headache, diagnosed with slit-lamp that showed cells in the anterior chamber. He was treated with steroid eye drops and mydriatics. At the same time, he presented arthritis of the left ankle, progressing into oligoarticular extended form with arthritis of the knees, left elbow, left shoulder, left wrist and the small joints of the hands and feet. The patient was treated with injections of triamcinolone hexacetonide1 $\mathrm{mg} / \mathrm{kg}$ into the left ankle and both knees.

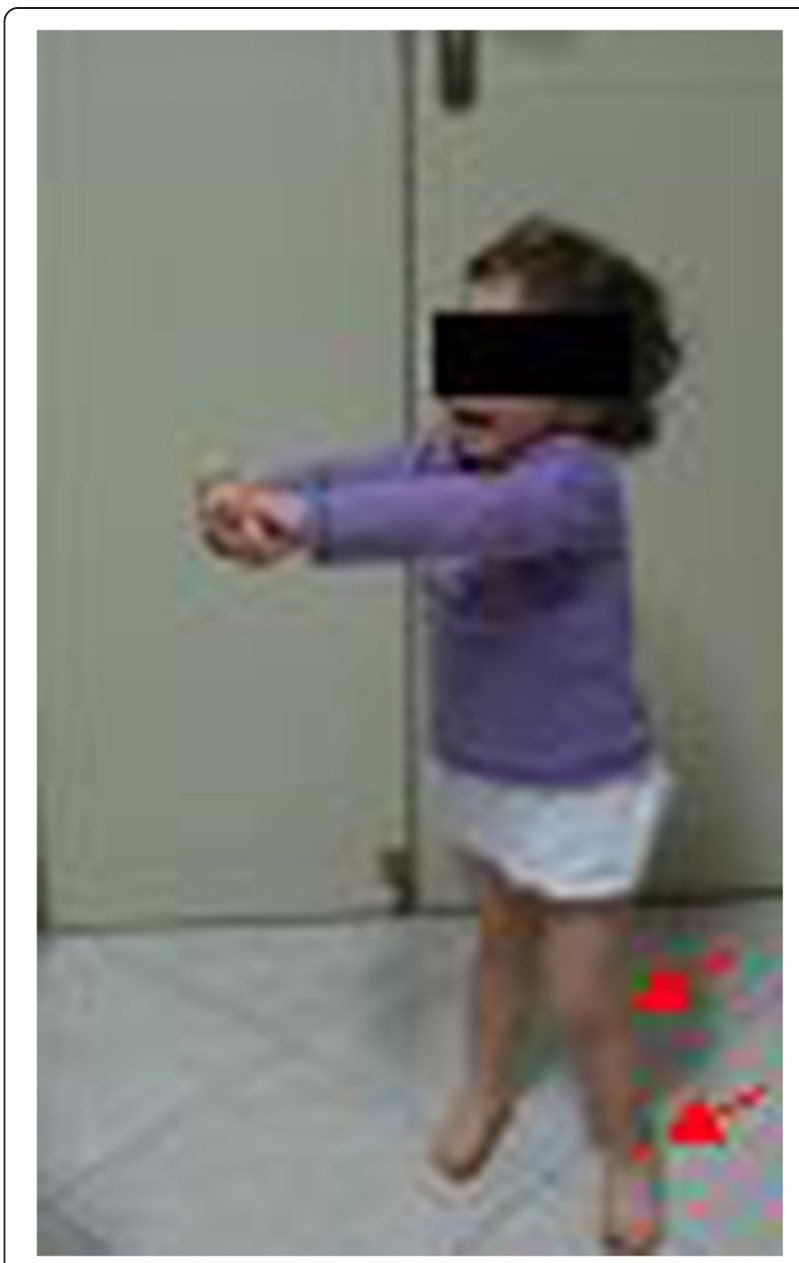

Figure 3 Case 1 (age 2 years). Photograph patient with juvenile idiopathic arthritis with fixed flexion contraction of the left leg for active knee and ankle joints arthritis (red arrows).

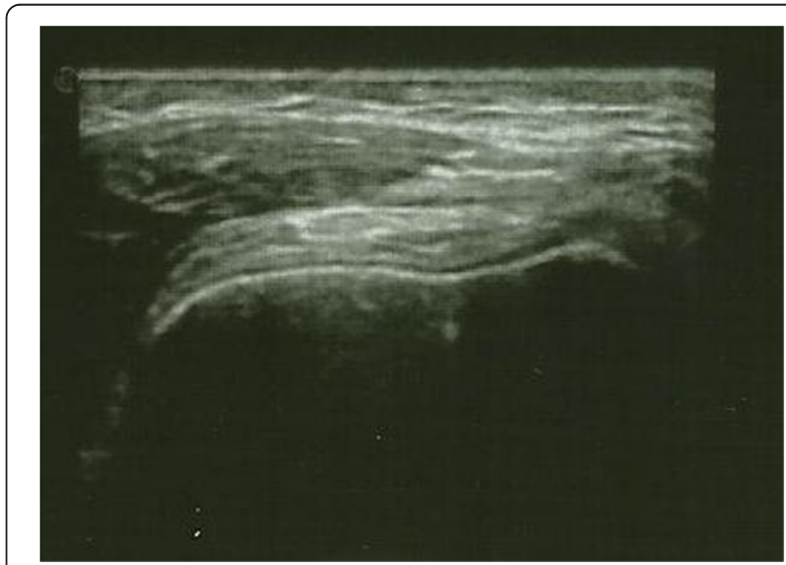

Figure $\mathbf{4}$ Case $\mathbf{1}$ left knee ultrasound after treatment. Left knee: transverse gray-scale $12-5 \mathrm{MHz}$ ultrasound image obtained over the medial aspect of the knee showing normal aspect of the joint without fluid or synovial pannus into the subquadriceps recess. 


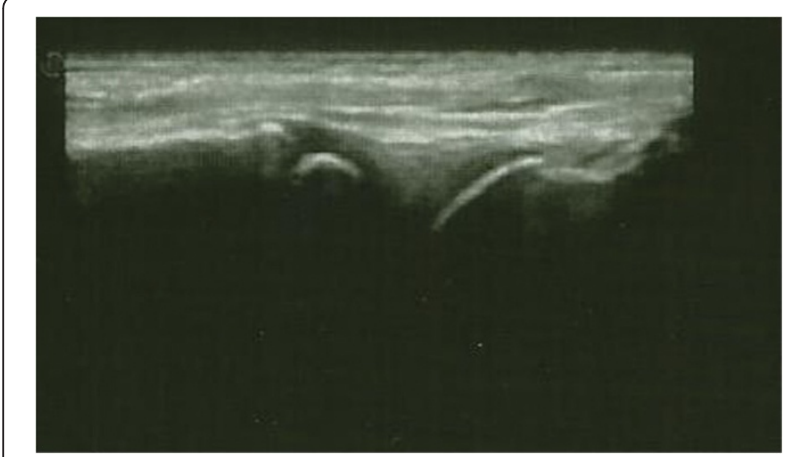

Figure 5 Case 1 left ankle ultrasound after treatment.

Midsagittal12 - $5 \mathrm{MHz}$ US image over the dorsal ankle showing normal joint recess, without hypoechoic fluid or synovial pannus.

At 2 years of age (July 2005) he had a bilateral uveitis flare and was started on oral prednisone $1 \mathrm{mg} / \mathrm{kg} /$ day and subcutaneous methotrexate $10 \mathrm{mg} / \mathrm{m}^{2} /$ week. Between November 2008 and July 2011 the patient was treated with infliximab, and had a good response for 2 years, but then experienced a number of relapses of uveitis. Therefore, in August 2011, he was switched to adalimumab 20 mg every 2 weeks.

On his most recent presentation, the patient was admitted to hospital with relapsed uveitis and arthritis of the right knee (limited range of motion and pain) while being treated with prednisone $0.5 \mathrm{mg} / \mathrm{kg} /$ day, adalimumab $20 \mathrm{mg}$ every 2 weeks and methotrexate $10 \mathrm{mg} /$ week. In October 2012, the dosages of both adalimumab and methotrexate were progressively increased based on body surface area $\left(\mathrm{m}^{2}\right)$ : adalimumb to $25 \mathrm{mg}$ every 2 weeks (specific paediatric formulation $24 \mathrm{mg} / \mathrm{m}^{2}$ every 2 weeks) and methotrexate to $15 \mathrm{mg} /$ week $\left(15 \mathrm{mg} / \mathrm{m}^{2} /\right.$ week $)$. The corticosteroid dosage was progressively tapered to withdrawal over the next 6 months without any flare of uveitis. The patient has maintained clinical remission for the last 6 months receiving ongoing therapy with adalimumab $24 \mathrm{mg} / \mathrm{m}^{2}$ every 2 weeks, based on surface area using specific pediatric formulation, and with MTX $15 \mathrm{mg} / \mathrm{m}^{2} /$ week.

\section{Case 3}

A 5-year-old girl was referred in August 2008 for management of arthritis. The patient had severe swelling and limited range of motion in the right ankle, slight swelling and slight effusion in the right knee with full range of motion, and slight swelling of the right wrist and the fourth metacarpo-phalangeal joint of the left hand. Physical examination was otherwise unremarkable. Laboratory tests showed high ESR $(64 \mathrm{~mm} / \mathrm{h})$ and ANA positivity, with a titer of 1:640 and homogeneous pattern. Though in the absence of ocular symptoms, eye evaluation with slitlamp examination was positive for signs of iridociclitis, showing cells in the anterior chamber with initial band

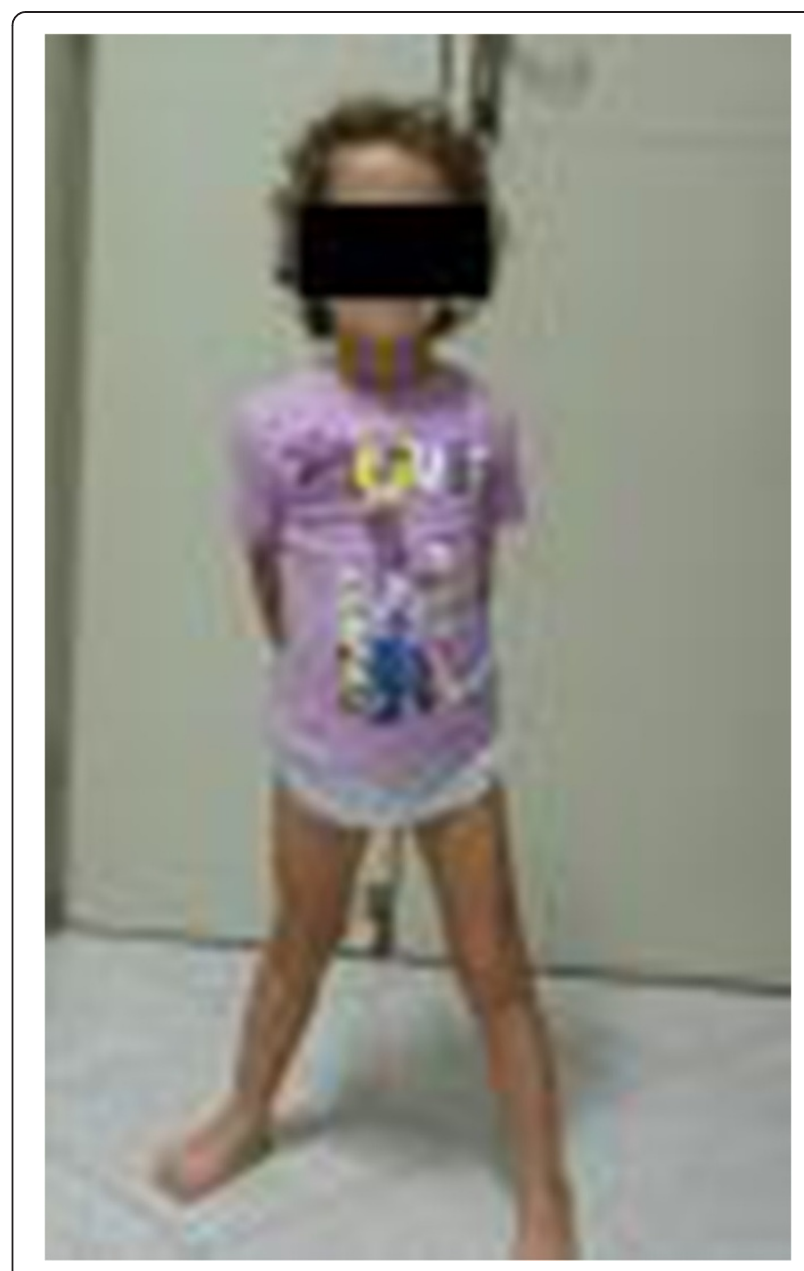

Figure 6 Case 1 after 2 years of ongoing adalimumab treatment. Photograph showing patient in remission at 4 years of age.

keratopathy and sinechiae; visual acuity was normal. A diagnosis of ANA positive-JIA was made and naproxen, corticosteroid eye drops and mydriatics were prescribed. Three weeks later the patient showed a partial response to treatment, and slit-lamp examination showed no signs of active uveitis but persistent band keratopathy and sinechie. Subcutaneous methotrexate $12.5 \mathrm{mg} / \mathrm{m}^{2} /$ week was then initiated.

In October 2008 physical exam revealed severe swelling of the right wrist with limitation in the range of motion, and swelling of the fourth left metacarpo-phalangeal joint. The diagnosis of polyarticular JIA was confirmed, NSAIDS were stopped and prednisone $1 \mathrm{mg} / \mathrm{kg} /$ day was started then rapidly tapered over the next two weeks. Two months later the patient showed a good response with an unremarkable physical examination and no active uveitis. From May 2010 to September 2010 the patient experienced three flares of uveitis that were treated with local corticosteroids and mydriatics; physical exam on these occasions revealed no signs of arthritis and laboratory findings were normal. However, 
given the high rate of uveitis flares, the decision was made to add subcutaneous adalimumab $24 \mathrm{mg} / \mathrm{m}^{2}$ every 2 weeks to the ongoing therapy with methotrexate. After two other episodes of uveitis (November 2010 and March 2011) that responded well to local therapy, the patient has shown no signs of either arthritis or uveitis during regular follow-up since March 2011. Methotrexate therapy was tapered and then stopped in December 2012, and adalimumab was continued. In February 2013 adalimumab was stopped and the patient has remained free of arthritis and uveitis since then. Both methotrexate and adalimumab were well tolerated, with no clinical or laboratory signs of adverse effects.

\section{Discussion}

We have described three children with JIA and uveitis who responded well to adalimumab therapy. All were treated with the pediatric formulation of adalimumab with dosing based on body surface area. The main evidence for use of adalimumab in children with JIA has come from a randomized, controlled trial in patients with polyarticular disease [25]. Other anti-TNF agents have also shown benefits in these patients [26,27].

A critical issue in the management of JIA is co-morbid uveitis that is often refractory to conventional DMARDs and require high dose glucocorticoids. Recently, anti-TNF agents, including infliximab and adalimumab, have shown to be very effective in JIA patients who present with refractory uveitis [28-38].

Although an indirect comparison showed that adalimumab and infliximab were equally efficacious in terms of response to treatment and for the prevention of disease flare, adalimumab appeared to be more effective and better tolerated than infliximab, as evidenced by recent data from the National Italian Registry of childhood chronic uveitis associated with JIA and from other published experiences [38-40]. Moreover, an open-label prospective, comparative, multicenter cohort study of childhood noninfectious chronic uveitis, with 22 children with uveitis associated with JIA (12 treated with Adalimumab and 10 with Infliximab), confirmed that over 3 years of treatment, adalimumab is more efficacious than infliximab in maintaining remission of chronic childhood uveitis [36]. Recently, Simonini et al., even if limited to a relatively small group, showed a better efficacy of Adalimumab when used as first anti- TNF alpha treatment in childhood chronic uveitis [37].

In contrast, etanercept has been reported not to halt the onset of uveitis or to be more effective than placebo $[41,42]$, and some reports of new-onset uveitis associated with etanercept use in JIA have been published [43].

In fact, infliximab has been shown to be better than etanercept in children with ankylosing spondylitis and anterior uveitis and, in patients with JIA and uveitis, adalimumab showed better outcome than etanercept $[28,44]$. For these reasons, etanercept is not considered to be effective in treating intraocular inflammation [45].

We hypothesize that these monoclonal antibodies (adalimumab and infliximab) would be more effective in suppressing ocular inflammation than etanercept, which is a synthetic receptor for TNF- $\alpha$ and does not act against cellbound TNF.

We also suppose that adalimumab would provide a superior response than infliximab in maintaining remission, because it binds to TNF- $\alpha$ on the cell surface and not just in the circulation.

For the reasons mentioned above, adalimumab was chosen in these three patients. Patient 2 in this case series had a better response to adalimumab therapy after loss of efficacy of infliximab. Increasing the dosage of adalimumab based on body surface area resulted in achievement of good therapeutic activity in this patient. When treating JIA, it is recommended that methotrexate is given with adalimumab to optimize outcomes [25]. All three cases in this report were receiving methotrexate at the time of adalimumab initiation.

Both methotrexate and adalimumab have corticosteroidsparing properties, and systemic corticosteroid therapy was tapered and then withdrawn in all three cases. This was particularly notable in case 2 , who had corticosteroid-dependent disease. Withdrawal of corticosteroids in the youngest patient (case 1) allowed catch-up growth to occur. The positive effect of anti-TNF agents on disease control, and subsequently on the growth of children with JIA, is a particularly attractive feature of this approach to JIA management. Besides, in case 1 patient, when treatment was initiated, use of adalimumab in the 2-year-old girl was off-label, because, at that time, adalimumab was only approved in Italy for use in JIA patients aged 4-17 years. But now, the authorization is extended for JIA patients over 2 years old.

Certainly, good results in terms of uveitis outcome were seen in our three cases. A recent survey of US pediatric rheumatologists on the treatment of patients with JIA revealed that anti-TNF agents were used more often in those with versus without co-morbid uveitis [40]. The coexistence of JIA and uveitis was a contributing factor to the decision to use adalimumab in case 3 . This patient was then able to stop methotrexate treatment, and ultimately adalimumab, without relapse of either JIA or uveitis. However, the follow-up period is not yet long enough to make a definite statement about the ability of adalimumab to induce long-term drug-free remission in this patient. The other two patients achieved remission and continued to receive adalimumab and methotrexate.

Our three patients tolerated adalimumab very well; no clinical or laboratory adverse events were documented. There are, however, well-known risks associated with antiTNF agents, including re-activation of latent tuberculosis infection. This risk is managed by pre-treatment screening. 
In addition, malignancy has been reported in children who have been treated with adalimumab, etanercept or infliximab [46]. However it is difficult to determine if this risk is due to the biologic therapy or determined by the concomitant use of other immunosuppressive drugs, or by the higher risk of malignancy in patients with JIA [47]. Such data underscore the importance of large-scale, coordinated, national and international pharmaco-vigilance programs for better quantifying the risks and benefits of anti-TNF therapy in children. Future analyses also need to take into account the high cost of biological therapies, and therefore the costeffectiveness of this approach to treatment.

\section{Conclusions}

We have reported herein the case details of three children with JIA and chronic uveitis treated with adalimumab. These three children had good outcomes after the addition of adalimumab to their treatment regimen. Our data, from routine clinical practice, and in agreement with clinical trials, further support the use of biologic therapy for the management of JIA and uveitis, not responder to DMARDs, in children over two years of age. Long-term follow-up, both from registries and clinical trials, will help to further elucidate the ongoing efficacy and tolerability of adalimumab, and other biologic drugs, in these patients.

\section{Consent}

Written informed consent was obtained from the patients' parents or legal guardians for publication of these Case Reports and any accompanying images. A copy of the written consent is available for review by the Editorin-Chief of this journal.

\section{Abbreviations \\ ANA: Antinuclear antibody; DMARDs: Disease-modifying anti-rheumatic drugs; ESR: Erythrocyte sedimentation rate; HLA: Human lymphocyte antigen; ILAR: International League Against Rheumatism; JIA: Juvenile idiopathic arthritis; NSAIDs: Non-steroidal anti-inflammatory drugs; RF: Rheumatoid factor; TNF-a: Tumour necrosis factor-alpha.}

\section{Competing interests}

The authors declare that they have no competing interests.

\section{Authors' contributions}

All the authors were involved in this report. FLT and FI wrote the manuscript, FLT and FM cared for the case 1 patient. BT cared for case 2 patient, BT was responsible for data collection and manuscript preparation.MC and AM were involved in the care of patient 3, MC was responsible for data collection and manuscript preparation. All authors read and approved the final manuscript.

\section{Acknowledgements}

Medical writing assistance was provided by Nicola Ryan, independent medical writer.

The author thank the ophthalmologists who cared for these children for their cooperation: Silvana Guerriero (Ophthalmology Unit, Policlinic Hospital, University of Bari, Italy) cared for the case 1 patient, Paola Chiari (Ophthalmology Unit, L. Sacco Hospital, University of Milan, Italy) cared for the case 2 patient and Giuseppe Nascimbeni (Ophthalmology Clinic, University of Brescia and Spedali Civili of Brescia, Italy) cared for the case 3 patient.

\section{Author details}

${ }^{1}$ Department of Paediatrics, Antonio Perrino Hospital, Brindisi, Italy. ${ }^{2}$ Pediatric Clinic University of Brescia and Spedali Civili di Brescia, Brescia, Italy. ${ }^{3}$ Rheumatology Unit, L. Sacco University Hospital, Milan, Italy. ${ }^{4}$ Policlinic Hospital, Rheumatology Unit, University of Bari, Bari, Italy.

Received: 18 March 2014 Accepted: 14 May 2014

Published: 24 May 2014

\section{References}

1. Petty RE, Southwood TR, Manners P, Baum J, Glass DN, Goldenberg J, He X, Maldonado-Cocco J, Orozco-Alcala J, Prieur AM, Suarez-Almazor ME, Woo P, International League of Associations for Rheumatology: International League of Associations for Rheumatology classification of juvenile idiopathic arthritis: second revision, Edmonton, 2001. J Rheumatol 2004, 31:390-392.

2. Petty RE, Southwood TR, Baum J, Bhettay E, Glass DN, Manners P, Maldonado-Cocco J, Suarez-Almazor M, Orozco-Alcala J, Prieur AM: Revision of the proposed classification criteria for juvenile idiopathic arthritis: Durban, 1997. J Rheumatol 1998, 25(10):1991-1994.

3. Ravelli A, Marini A: Juvenile idiopathic arthritis. Lancet 2007, 369(9563):767-778

4. Borchers AT, Selmi C, Cheema G, Keen CL, Shoeneld Y, Gershwin ME: Juvenile idiopathic arthritis. Autoimmun Rev 2006, 5:279-298.

5. Gaspari S, Marcovecchio ML, Breda L, Chiarelli F: Growth in juvenile idiopathic arthritis: the role of inflammation. Clin Exp Rheumatol 2011, 29(1):104-110.

6. Petty RE, Cassidy JT: Chronic arthritis in childhood. In Textbook of Pediatric Rheumatology. 6th edition. Philadelphia: W.B. Saunders; 2011:211-235.

7. Ruperto N, Murray KJ, Gerloni V, Wilffraat N, de Oliveira SK, Falcini F, Dolezalova P, Alessio M, Burgos-Vargas R, Corona F, Vesely R, Foster $\mathrm{H}$ Davidson J, Zulian F, Asplin L, Baildam E, Consuegra JG, Ozdogan H, Saurenmann R, Joos R, Pistorio A, Woo P, Martini A, Pediatric Rheumatology International Trials Organization: A randomized trial of parenteral methotrexate comparing an intermediate dose with a higher dose in children with juvenile idiopathic arthritis who failed to respond to standard doses of methotrexate. Arthritis Rheum 2004, 50(7):2191-2201.

8. Beresord MW, Baildam EM: New advances in the management of juvenile idiopathic arthritis: II. The era of biological. Arch Dis Child Educ Pract Ed 2009, 94(5):151-156.

9. Ungar WJ, Costa V, Burnett HF, Feldman BM, Laxer RM: The use of biologic response modifiers in polyarticular-course juvenile idiopathic arthritis: a systemic review. Semin Arthritis Rheum 2013, 42:597-618.

10. Boiu S, Marniga E, Bader-Meunier B, Mouy R, Compeyrot-Lacassagne S, Quartier P, Wouters CH: Functional status in severe juvenile idiopathic arthritis in the biologic treatment era: an assessment in a French paediatric rheumatology referral centre. Rheumatology 2012, 51(7):1285-1292.

11. Beukelman T, Patkar NM, Saag KG, Tolleson-Rinehart S, Cron RQ, DeWitt EM, Ilowite NT, Kimura Y, Laxer RM, Lovell DJ, Martini A, Rabinovich CE, Ruperto N: 2011 American College of Rheumatology recommendations for the treatment of juvenile idiopathic arthritis: initiation and safety monitoring of therapeutics agents for the treatment of arthritis and systemic features. Arthritis Care Res 2011, 63(4):465-482.

12. Murray PI, Sivaraj RR: Anti-TNF-alpha therapy for uveitis: Behçet and beyond. Eye 2005, 19:831-838.

13. Santos Lacomba M, Marcos Martín C, Gallardo Galera JM, Gómez Vidal MA Collantes-Estévez E, RamírezChamond R, Omar M: Aqueous humor and serum tumour necrosis factor-alpha in clinical uveitis. Ophthalmic Res 2001, 33:251-255.

14. Pérez-Guijo V, Santos-Lacomba M, Sánchez-Hernández M, Castro-Villegas Mdel C, Gallardo-Galera JM, Collantes-Estévez E: Tumour necrosis factoralpha levels in aqueous humor and serum from patients with uveitis: the involvement of HLA-B27. Curr Med Res Opin 2004, 20:155-157.

15. Thorne JE, Woreta FA, Dunne JP, Jabs DA: Risk of cataract development among children with juvenile idiopathic arthritis-related uveitis treated with topical corticosteroids. Ophthalmology 2010, 117(7):1436-1441.

16. Marvillet I, Terrada C, Quartier P, Quoc EB, Bodaghi B, Prieur AM: Ocular threat in juvenile idiopathic arthritis. Joint Bone Spine 2009, 76:383-388.

17. Smith JA, Mackensen F, Sen HN, Leigh JF, Watkins AS, Pyatetsky D, Tessler HH, Nussenblatt RB, Rosenbaum JT, Reed GF, Vitale S, Smith JR, Goldstein DA Epidemiology and course of disease in childhood uveitis. Ophthalmology 2009, 116:1544-1551. e1. 
18. Kanski JJ: Uveitis in juvenile chronic arthritis: incidence, clinical features and prognosis. Eye (Lond) 1988, 2:641-645.

19. Saurenmann RK, Levin AV, Feldman BM, Rose JB, Laxer RM, Schneider R, Silverman ED: Prevalence, risk factors, and outcome of uveitis in juvenile idiopathic arthritis: a long-term follow-up study. Arthritis Rheum 2007, 56:647-657.

20. Chia A, Lee V, Graham EM, Edelsten C: Factors related to severe uveitis at diagnosis in children with juvenile idiopathic arthritis in a screening program. Am J Ophthalmol 2003, 135:757-762.

21. Holland GN, Denove CS, Yu F: Chronic anterior uveitis in children: clinical characteristics and complications. Am J Ophthalmol 2009, 147:667-678. e5.

22. Woreta F, Thorne JE, Jabs DA, Kedhar SR, Dunn JP: Risk factors for ocular complications and poor visual acuity at presentation among patients with uveitis associated with juvenile idiopathic arthritis. Am J Ophthalmol 2007, 143:647-655.

23. Edelsten C, Lee V, Bentley CR, Kanski JJ, Graham EM: An evaluation of baseline risk factors predicting severity in juvenile idiopathic arthritis associated uveitis and other chronic anterior uveitis in early childhood. Br J Ophthalmol 2002, 86:51-56.

24. Thorne JE, Woreta F, Kedhar SR, Dunn JP, Jabs DA: Juvenile idiopathic arthritis-associated uveitis: incidence of ocular complications and visual acuity loss. Am J Ophthalmol 2007, 143:840-846.

25. Lovell DJ, Ruperto N, Goodman S, Reiff A, Jung L, Wouters C, Silverman ED, Balogh Z, Henrickson M, Apaz MT, Baildam E, Fasth A, Gerloni V, Lahdenne P, Prieur AM, Ravelli A, Saurenmann RK, Gamir ML, Wulffraat N, Marodi L, Petty RE, Joos R, Zulian F, McCurdy D, Myones BL, Nagy K, Reuman P, Szer I, Travers S, Beutler A, et al: Adalimumab with or without methotrexate in juvenile rheumatoid arthritis. N Engl J Med 2008, 359(8):810-820.

26. Ruperto N, Lovell DJ, Cuttica R, Wilkinson N, Woo P, Espada G, Wouters C, Silverman ED, Balogh Z, Henrickson M, Apaz MT, Baildam E, Fasth A, Gerloni V, Lahdenne P, Prieur AM, Ravelli A, Saurenmann RK, Gamir ML, Wulffraat N, Marodi L, Petty RE, Joos R, Zulian F, McCurdy D, Myones BL, Nagy K, Reuman P, Szer I, Travers S, et al: A randomized, placebo-controlled trial of infliximab plus methotrexate for the treatment of polyarticular-course juvenile rheumatoid arthritis. Arthritis Rheum 2007, 56:3096-3106.

27. Lovell DJ, Giannini EH, Reiff A, Cawkwell GD, Silverman ED, Nocton JJ, Stein LD, Gedalia A, llowite NT, Wallace CA, Whitmore J, Finck BK: Etanercept in children with polyarticular juvenile rheumatoid arthritis. N Engl J Med 2000, 342:763-769.

28. Biester S, Deuter C, Michels H, Haefner R, Kuemmerle-Deschner J, Doycheva D, Zierhut M: Adalimumab in the therapy of uveitis in childhood. Br J Ophthalmol 2007, 91(3):319-324.

29. Neri P, Zucchi M, Allegri P, Lettieri M, Mariotti C, Giovannini A: Adalimumab (Humira $^{\text {TM }}$ ): a promising monoclonal anti-tumor necrosis factor alpha in ophthalmology. Int Ophthalmol 2011, 31(2):165-173.

30. Foeldvari I, Nielsen S, Kümmerle-Deschner J, Espada G, Horneff G, Bica B, Olivieri AN, Wierk A, Saurenmann RK: Tumor necrosis factor-a blocker in treatment of juvenile idiopathic arthritis-associated uveitis refractory to second-line agents: results of a multinational survey. J Rheumatol 2007, 34:1146-1150.

31. Tynjala P, Kotaniemi K, Lindahl P, Latva K, Aalto K, Honkanen V: Adalimumab in juvenile idiopathic arthritis associated chronic anterior uveitis. Rheumatology 2008, 47:339-344.

32. Vazquez-Cobian LB, Flynn T, Lehman TJ: Adalimumab therapy for childhood uveitis. J Pediatr 2006, 149(4):572-575.

33. Díaz-Llopis M, Salom D, Garcia-de-Vicuña C, Cordero-Coma M, Ortega G, Ortego N, Suarez-de-Figueroa M, Rio-Pardo MJ, Fernandez-Cid C, Fonollosa A, Blanco R, Garcia-Aparicio AM, Benitez-Del-Castillo JM, Olea JL, Arevalo JF: Treatment of refractory uveitis with adalimumab: a prospective multicenter study of 131 patients. Ophthalmology 2012, 119(8):1575-1581.

34. Kotaniemi K, Säilä H, Kautiainen H: Long-term efficacy of adalimumab in the treatment of uveitis associated with juvenile idiopathic arthritis. Clin Ophthalmol 2011, 5:1425-1429.

35. Magli A, Forte R, Navarro P, Russo G, Orlando F, Latanza L, Alessio M: Adalimumab for juvenile idiopathic arthritis-associated uveitis. Graefes Arch Clin Exp Ophthalmol 2013, 251(6):1601-1606.

36. Simonini G, Taddio A, Cattalini M, Caputo R, De Libero C, Naviglio S, Bresci C, Lorusso M, Lepore L, Cimaz R: Prevention of flare recurrences in childhoodrefractory chronic uveitis: an open-label comparative study of adalimumab versus infliximab. Arthritis Care Res 2011, 63(4):612-618.
37. Simonini G, Taddio A, Cattalini M, Caputo R, de Libero C, Parentin F, Pagnini I, Lepore L, Cimaz R: Superior efficacy of adalimumab in treating childhood refractory chronic uveitis when used as first biologic modifier drug: adalimumab as starting anti-TNF-alpha therapy in childhood chronic uveitis. Pediatr Rheumatol 2013, 11(1):16.

38. Zannin ME, Birolo C, Gerloni VM, Miserocchi E, Pontikaki I, Paroli MP, Bracaglia C, Shardlow A, Parentin F, Cimaz R, Simonini G, Falcini F, Corona F, Viola S, De Marco R, Breda L, La Torre F, Vittadello F, Martini G, Zulian F: Safety and efficacy of infliximab and adalimumab for refractory uveitis in juvenile idiopathic arthritis: 1-year follow-up data from the Italian Registry. J Rheumatol 2013, 40(1):74-79.

39. Otten MH, Anink J, Spronk S, van Suijlekom-Smit LW: Efficacy of biological agents in juvenile idiopathic arthritis: a systematic review using indirect comparisons. Ann Rheum Dis 2013, 72(11):1806-1812.

40. Beukelman T, Ringold S, Davis TE, DeWitt EM, Pelajo CF, Weiss PF, Kimura Y CARRA Registry Investigators: Disease-modifying anti-rheumatic drug use in the treatment of juvenile idiopathic arthritis: a cross-sectional analysis of the CARRA Registry. J Rheumatol 2012, 39(9):1867-1874.

41. Schmeling $H$, Horneff $G$ : Etanercept and uveitis in patients with juvenile idiopathic arthritis. Rheumatology (Oxford) 2005, 44:1008-1011.

42. Smith JA, Thompson DJ, Whitcup SM, Suhler E, Clarke G, Smith S, Robinson M, Kim J, Barron KS: A randomized, placebo-controlled, double-masked clinical trial of etanercept for the treatment of uveitis associated with juvenile idiopathic arthritis. Arthritis Rheum 2005, 53:18-23.

43. Taban M, Dupps WJ Jr, Mandell B, Perez VL: Etanercept (Enbrel)-associated inflammatory eye disease: case report and review of the literature. Ocul Immunol Inflamm 2006, 14:145-150.

44. Braun J, Baraliakos X, Listing J, Sieoer J: Decreased incidence of anterior uveitis in patients with ankylosing spondylitis treated with anti-tumor necrosis factor agents infliximab and etanercept. Arthritis Rheum 2005 52:2447-2451.

45. Saurenmann RK, Levin AV, Rose JB, Parker S, Rabinovitch T, Tyrrell PN, Feldman BM, Laxer RM, Schneider R, Silverman ED: Tumour necrosis factor a inhibitors in the treatment of childhood uveitis. Rheumatology (Oxford) 2006, 45:982-989.

46. Diak P, Siegel J, La Grenade L, Choi L, Lemery S, McMahon A: Tumor necrosis factor alpha blockers and malignancy in children: forty-eight cases reported to the Food and Drug Administration. Arthritis Rheum 2010, 62(8):2517-2524

47. Beresford MW: Juvenile idiopathic arthritis. New insights into classification, measures of outcome, and pharmaco-therapy. Pediatr Drugs 2011, 13(3):161-173.

doi:10.1186/1756-0500-7-316

Cite this article as: La Torre et al:: Efficacy of adalimumab in young

children with juvenile idiopathic arthritis and chronic uveitis: a case series. BMC Research Notes 2014 7:316.

\section{Submit your next manuscript to BioMed Central and take full advantage of:}

- Convenient online submission

- Thorough peer review

- No space constraints or color figure charges

- Immediate publication on acceptance

- Inclusion in PubMed, CAS, Scopus and Google Scholar

- Research which is freely available for redistribution 